\title{
Erratum to: Two-year adjuvant imatinib mesylate after complete resection of localized, high-risk GIST with KIT exon 11 mutation
}

\author{
Yoon-Koo Kang • Byung Woog Kang • Seock-Ah Im • Jae-Lyun Lee • \\ Sook Ryun Park • Won Ki Kang • Heung Moon Chang • Tae Won Kim • \\ Do-Youn Oh $\cdot$ Kyung Hae Jung $\cdot$ Min-Hee Ryu
}

Published online: 13 January 2013

(c) Springer-Verlag Berlin Heidelberg 2013

\section{Erratum to: Cancer Chemother Pharmacol (2013) \\ 71:43-51 \\ DOI 10.1007/s00280-012-1970-3}

Unfortunately, Fig. 3b, c were inadvertently swapped in the online published article. The correct version of Fig. 3 is placed in the following page.
The online version of the original article can be found under doi:10.1007/s00280-012-1970-3.

\section{Y.-K. Kang $(\bowtie) \cdot$ B. W. Kang $\cdot$ J.-L. Lee}

H. M. Chang - T. W. Kim - M.-H. Ryu

Department of Oncology, University of Ulsan College of Medicine, Asan Medical Center, 88, Olympic-ro 43-gil, Songpa-gu, Seoul 138-736, Korea

e-mail: ykkang@amc.seoul.kr

\section{S.-A. Im · D.-Y. Oh}

Department of Internal Medicine, Seoul National University Hospital, Seoul National University College of Medicine,

28 Yongon-Dong, Chongno-Gu, Seoul 110-744, Korea

\section{S. R. Park}

Center for Gastric Cancer, Research Institute and Hospital, National Cancer Center, 809 Madu1-dong, Ilsandong-gu,

Goyang-si, Gyeonggi-do 411-769, Korea

\section{W. K. Kang}

Department of Medicine, Sungkyunkwan University School of Medicine, Samsung Medical Center, 50 Irwon-dong,

Kangnam-gu, Seoul 135-710, Korea

\author{
K. H. Jung \\ Center for Colorectal Cancer, Research Institute and Hospital, \\ National Cancer Center, 809 Madu1-dong, Ilsandong-gu, \\ Goyang-si, Gyeonggi-do 411-769, Korea \\ Present Address: \\ K. H. Jung \\ Department of Oncology, University of Ulsan College \\ of Medicine, Asan Medical Center, 88, Olympic-ro 43-gil, \\ Songpa-gu, Seoul 138-736, Korea \\ Present Address: \\ B. W. Kang \\ Department of Hematology/Oncology, Kyungpook National \\ University School of Medicine, Kyungpook National University \\ Hospital, 474, Hakjeongdong, Buk-gu, Daegu 702-210, Korea
}


Fig. 3 Kaplan-Meier analysis of recurrence-free survival: a according to group categorization by size and mitotic count, $\mathbf{b}$ according to the type of KIT exon 11 mutations, c according to the site of primary tumor
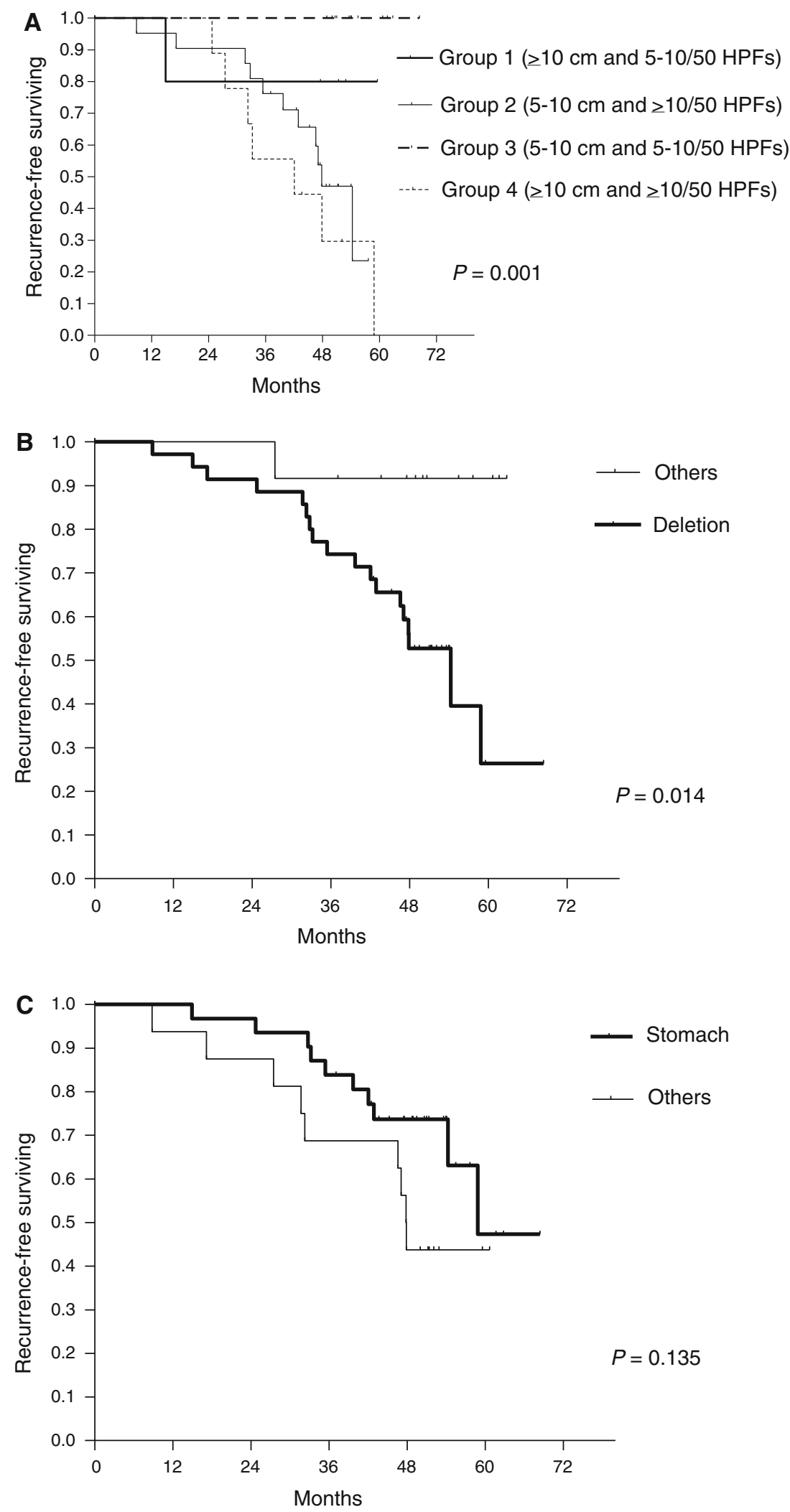